BMJ Open Sport \& Exercise Medicine

\title{
Intersection syndrome: an acute surgical disease in elite rowers
}

\author{
Gregory Hoy, ${ }^{01}$ Larissa Trease, ${ }^{2}$ Wendy Braybon (Deceased) ${ }^{3}$
}

To cite: Hoy G, Trease L, Braybon (Deceased) W. Intersection syndrome: an acute surgical disease in elite rowers. BMJ Open Sport \& Exercise Medicine 2019;5:e000535. doi:10.1136/ bmjsem-2019-000535

Accepted 16 May 2019
Check for updates

\section{(C) Author(s) (or their} employer(s)) 2019. Re-use permitted under CC BY-NC. No commercial re-use. See rights and permissions. Published by BMJ.

${ }^{1}$ Melbourne Orthopaedic Group, Melbourne, Victoria, Australia ${ }^{2}$ Emergency Department, Calvary Hospital Canberra, Canberra, Australian Capital Territory, Australia

${ }^{3}$ Victorian Institute of Sport, Melbourne, Victoria, Australia

Correspondence to Dr Gregory Hoy; gahoy@mog.com.au

\section{ABSTRACT}

Objective Intersection syndrome is a relatively common condition in elite rowers and continuing conjecture over its pathology and best management often includes prolonged withdrawal from training and changes to the technique that may affect rowing outcomes.

Methods We reviewed a case series in a national rowing squad and the effect on time loss produced by the condition. We reviewed the pathophysiology. We revisited the aggressive operative management put forward in the 1960s and applied it to modern rowing workload by reviewing a retrospective case series of six international rowers who had early surgical intervention.

Results Approximately $5 \%$ of the squad suffered intersection syndrome during a 3-year period. The effect on training time was between $20 \%$ and $40 \%$ of their training time in the period. Using our understanding of the pathology as a true tendinitis of the second wrist compartment caused by fascial compression from hypertrophied first compartment muscles, we advocated earlier surgery and almost immediate return to training, which occurred at a median of 7 days postsurgery. We had successful return in five of six rowers in an accelerated programme to minimise muscle wasting and technique modification caused by the condition, achieving career goals in a matter of weeks after surgical intervention. Conclusions We encourage early surgical management of intersection syndrome of the wrist to allow almost immediate return to training, and therefore interfere less with technique modification and time out of the water. This minimises career disruption in the elite rowing community.

\section{INTRODUCTION}

Intersection syndrome was described as peritendinitis crepitans by Howard in $1937^{1}$ and traumatic tenosynovitis in rowers by Williams in $1977 .^{2}$ Grundberg recognised hypertrophy of the first compartment associated with the activities of rowing and canoeing, but related the symptoms to stenosing tenosynovitis of the second compartment extensor wrist tendons rather than to the overlying bulky muscles. ${ }^{3}$ Theories proposed by other authors ${ }^{45}$ include tenovaginitis and compartment syndrome.

Rowing has long been recognised as a sport with a considerable load on the forearms. ${ }^{6}$ Biomechanical errors, rough water and changes in equipment have been blamed for

\section{What are the new findings?}

The pathophysiology of intersection syndrome is a true overuse tendinitis rather than tenosynovitis. Immediate surgery is effective for an urgent return to achieve career goals in elite rowing.

How might it impact on clinical practice in the near future?

Elite rowers presenting with intersection syndrome can expect full recovery without loss of training technique and form if they opt for an urgent surgical decompression with almost immediate return to full training.

the development of intersection syndrome ${ }^{7}$ in rowers. Fast flowing, choppy water and high winds increased the incidence of presentation in elite paddlers. ${ }^{8}$ Training reduced the likelihood of developing pathology with those who had covered more than $100 \mathrm{~km}$ per week for 8 weeks prior to racing having a lower incidence of injury.

The diagnosis of intersection syndrome is clinical with tenderness on palpation of the intersection point, $3-8 \mathrm{~cm}$ proximal to Lister's tubercle ${ }^{9}$ focal swelling and crepitus to both palpation and auscultation. ${ }^{7}$

Ultrasound in intersection syndrome demonstrates tendon thickening compared with the contralateral asymptomatic side, ${ }^{10}$ peritendinous oedema and synovial fluid within the tendon sheaths between the first and second compartments, and hypervascularity on Doppler sonography. ${ }^{10}$ MRI findings have concentrated on changes in the muscle of the first compartment as well as increased T2 signal, representing peritendinous oedema. ${ }^{91213}$

No publication has outlined an accurate pathogenesis in rowers. Wulle ${ }^{14}$ has described pathology similar to our findings in the German literature, where he suggested a thickened fascia from the first compartment as a cause for the symptoms. 
Most authors ${ }^{515}$ advocate a protracted period of conservative treatment with rest, activity modification, splinting and injection with corticosteroids.

While many rowers respond to a conservative treatment regime of icing, stretching and massage in the acute situation, many eventually modify their wrist biomechanics to decrease symptoms, ${ }^{16}$ but symptoms cause interruption to training schedules at times of increased workload prior to important (career goal) events. ${ }^{17}$

Classically, the decision to perform operative release is based on a failure of conservative treatment (at the expense of lost time training) and appropriate surgical indications. Surgery is usually the last resort, but if the procedure has minimal downtime and a low-risk profile, we propose that it should be considered earlier in the treatment programme in rowers at the elite level.

In this report, we demonstrate the pathology of the condition to clearly be a fascial response to first compartment hypertrophy producing an attrition synovial disruption of the sheaths over extensor carpi radialislongus (ECRL) and/or ECR brevis (ECRB), resulting in the classical 'audible crepitus' that defines this condition. We also show the dramatic improvement and rapid return to world-class performance with surgery and the rationale for this condition to be treated with the early surgical release.

\section{METHODS}

A review of cases presenting for treatment in the national squad was taken. The effect on training times was calculated. Assessment of prevalence and training loss was calculated over a 4-year period. After following

\begin{tabular}{lllll}
\hline Table 1 & Presentations in the national rowing squad \\
\hline Year & Cases & $\begin{array}{l}\text { \% of team } \\
\text { affected }\end{array}$ & $\begin{array}{l}\text { \% of } \\
\text { training time } \\
\text { affected }\end{array}$ & $\begin{array}{l}\text { Mean } \\
\text { days } \\
\text { lost }\end{array}$ \\
\hline 2010 & 3 & 6.1 & 0.5 & 34 \\
2011 & 3 & 5.5 & 0.7 & 16 \\
2012 & 2 & 4.3 & 0.9 & 26 \\
\hline
\end{tabular}

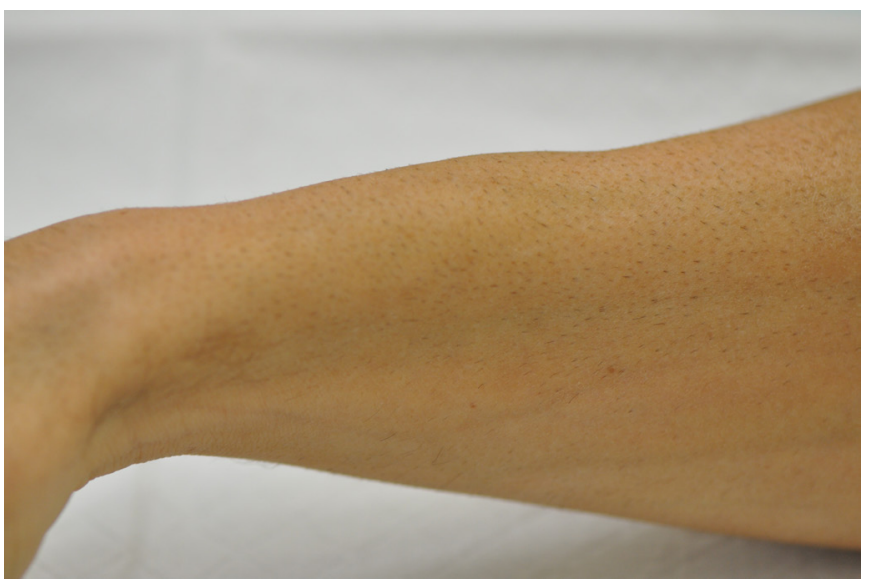

Figure 1 Swelling of first compartment muscles.
Table 2 Effect on total training

\begin{tabular}{lllll} 
Case & Year & Surgery & Days affected & $\begin{array}{l}\% \text { of total } \\
\text { training }\end{array}$ \\
\hline 1 & 2010 & Yes & 53 & 29.3 \\
2 & 2011 & No & 26 & 20.8 \\
3 & 2012 & Yes & 51 & 41.1 \\
\hline
\end{tabular}

this group and the surgical cases therein, we developed a more aggressive approach to diagnosis and earlier surgical assessment for rowers presenting with intersection syndrome. We have operated on six cases who presented in situations threatening 'career goal' events, such as world championships or Olympic regattas. A case review with operative photographs is demonstrated, and outcomes of all of these cases are presented.

\section{RESULTS}

\section{Prevalence}

Forearm intersection syndrome can generate a significant loss of on-water training time for an elite rower.

Table 1 presents the statistics of intersection syndrome cases in the Australian Rowing Team over 3 years. While the number of cases seems low (two or three each year), which represents between $4 \%$ and $6 \%$ of the team members. The percentage of training time affected by intersection syndrome across the whole team was between $0.5 \%$ and $0.9 \%$. Looking at individual cases perhaps gives a better perspective. Three cases are represented in table 2.

Having an athlete on no or modified training for between $20 \%$ and $40 \%$ of their personal available training time is a significant problem, not only for that athlete but also for the other members of that crew. We, thus, reviewed the concept of early surgery, and looked at a series of six surgically treated rowers with almost immediate return to training postoperatively.

\section{Clinical case example}

A 28-year-old male semi-professional rower at the Institute of Sport rowing programme presented 7 weeks prior to the commencement of the World Rowing Championships with wrist pain and crepitus on his dorsal wrist. He had recently joined the 'start-up crew' of his team, rowing stroke side and increasing his training sharply in preparation for the World Championships.

The rower presented for physiotherapy reporting right dorsal wrist pain with onset 3 days previously following some high intensity four kilometre pieces. Feathering the oar, gripping and supination aggravated the pain. Resisted wrist and thumb extension and abduction reproduced pain and crepitus. There was localised swelling.

Physiotherapy treatment included soft tissue massage of the muscle belly, radial nerve glides, regular icing, compression, bracing and topical Non-steroidal Anti-Inflammatory Drugs (NSAIDs) applied with plastic cling wrap. The athlete was restricted from training in the 


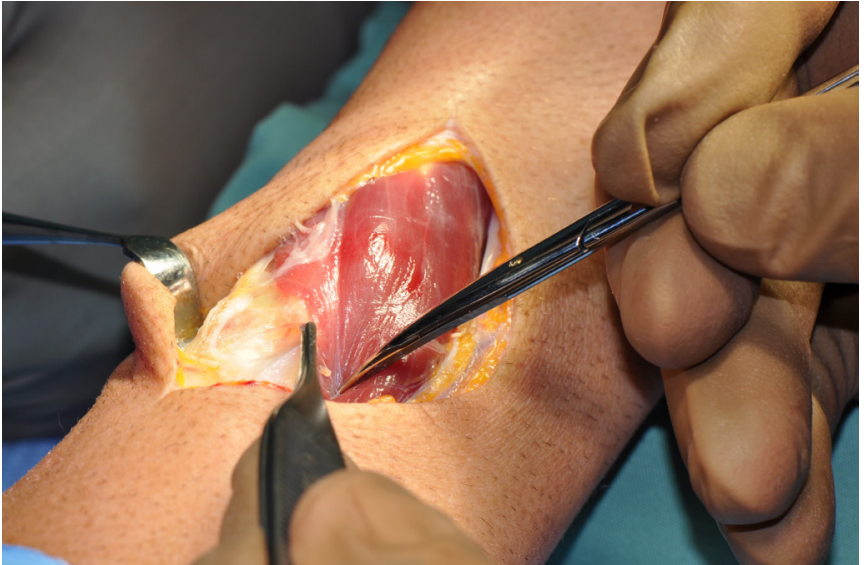

Figure 2 Superficial fascia removed at surgery.

boat and referred to elsewhere for a medical opinion regarding corticosteroid injection.

A gradual return to rowing over 1 week was planned following two corticosteroid injections and 10 days from the initial onset. The athlete reported rowing at $80 \%$ intensity. A referral was made for a surgical opinion.

At the time of surgical opinion, examination showed typical findings of intersection syndrome with relative prominence of the first compartment muscle bellies at the crossover over the wrist extensor tendons. Audible crepitus was noted, but moderate in nature. As his symptoms had not settled sufficiently with conservative measures, the rower decided to take the risk of surgery with early return to training in a final attempt to compete.

Surgical photos show the muscle prominence (figure 1), the muscle bellies (figure 2), the hole in the synovium of the second compartment tendons (figures 3 and 4) and the tendon changes under the synovium (figure 4). The tight band of fascia is partially visible at the upper end of the fascia of the Extensor Pollicis Brevis (EPB) muscle belly, where it has been rubbing on the synovial sheath of the ECRB tendon sheath; this was excised and sent for histological examination, and haemostasis secured

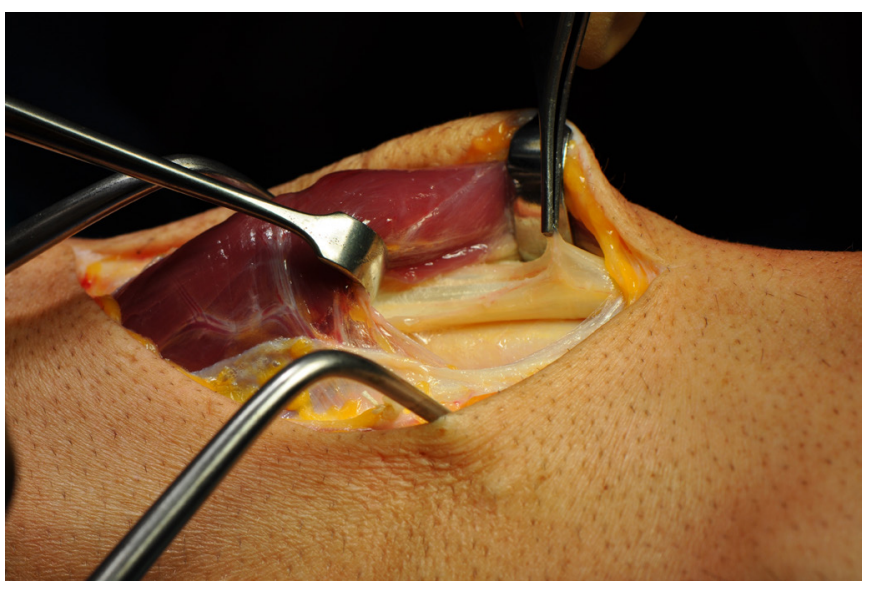

Figure 3 Perforation of second compartment synovial sheath under first compartment.

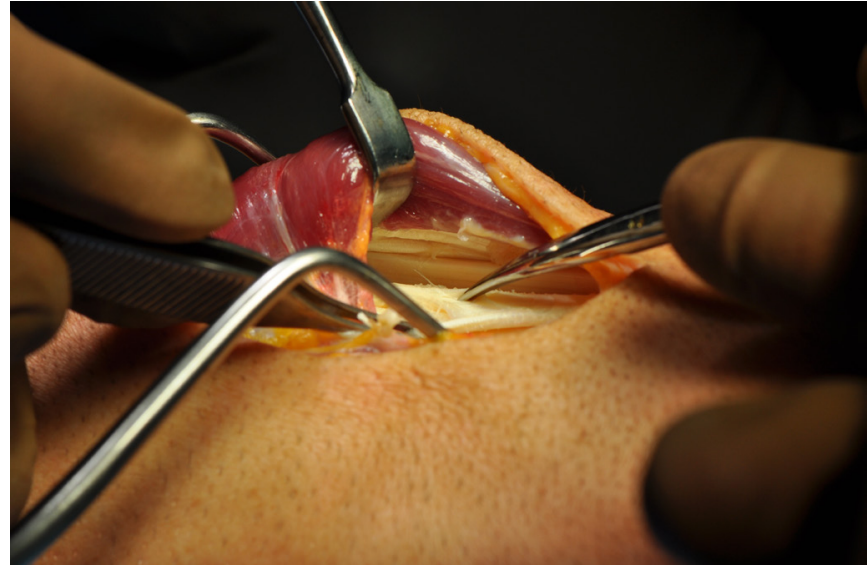

Figure 4 Roughened tendon surface after synovectomy.

prior to closure. The wound was closed with stitches that remained in situ for early training.

Histology of the excised tissue showed increased vascularity and chronic inflammatory changes in the stroma, with hyperplastic lining cells and fibrinous exudate over the synovial layer.

The patient returned to on-water training at 1 week, with a waterproof covering, and was able to continue in the team, winning a bronze medal in the final, 8 weeks after surgery. He returned after competition with no wound problems, and no pain some 10 weeks after surgery.

Four of the six surgical patients (see table 3 ) were operated on in the home country, while two were operated in the Olympic or competition city just prior to competitions, and after liaison with the senior author. Case 6 had a previous history of compartment syndrome in the contralateral arm treated successfully by surgical release 3 years earlier. Case 5 had mild ongoing crepitus following the operative intervention, which did not delay their return to ergo or on-water training. This athlete had an unrelated trauma to the operative region sustained while travelling, resulting in wound dehiscence at day 10 and subsequent issues that eventually resulted in temporary retirement from the sport.

\section{DISCUSSION}

Intersection syndrome typically occurs in rowers and paddlers, ${ }^{16} 17$ although there are reports of presentation in other sports, including tennis, skiing, sailing and weightlifting. ${ }^{5} 18-20$

Many theories of the pathogenesis of intersection syndrome include metastatic infection or toxic reaction to local infection. ${ }^{1}$ Howard's biopsies showed muscle oedema, and he has proposed a compartment syndrome without naming it, thus, as the cause of this condition. We found no evidence at the surgery to confirm this, nor the proposed mechanism of Grundberg and Reagan's that the pathologic lesion was a stenosing tenosynovitis of the second compartment tendons. ${ }^{3}$ Intraoperatively, we did not demonstrate the changes of tenovaginitis in 
Table 3 Surgical demographics and results

\begin{tabular}{|c|c|c|c|c|c|c|c|}
\hline Case & Year & Age & $\begin{array}{l}\text { Male/ } \\
\text { female }\end{array}$ & $\begin{array}{l}\text { Time } \\
\text { critical } \\
\text { surgery }\end{array}$ & $\begin{array}{l}\text { Days until } \\
\text { on water }\end{array}$ & $\begin{array}{l}\text { Early } \\
\text { results }\end{array}$ & $\begin{array}{l}\text { Long-term } \\
\text { (3-year) } \\
\text { follow-up }\end{array}$ \\
\hline 1 & 2010 & 28 & Male & Yes & 7 & Success & Excellent \\
\hline 2 & 2010 & 24 & Female & Yes & 5 & Success & Excellent \\
\hline 3 & 2012 & 29 & Female & Yes & 5 & Success & Excellent \\
\hline 4 & 2013 & 22 & Male & No & 7 & Success & Excellent \\
\hline 5 & 2013 & 26 & Male & Yes & 8 & $\begin{array}{l}\text { Crepitus that did not } \\
\text { change return to sport }\end{array}$ & $\begin{array}{l}\text { Retired } \\
\text { (Other reasons, see text) }\end{array}$ \\
\hline 6 & 2014 & 20 & Male & Yes & 7 & Success & Excellent \\
\hline
\end{tabular}

Success=rowed in the competition being prepared for postsurgery.

either first or second compartment sheaths as described by Burman. ${ }^{4}$ Histology, in our own cases, shows signs of inflammation, hypertrophy and fibrous hyperplasia.

Williams in his treatise on this condition in 1977 discussed returning rowers with intersection syndrome back to training in as little as 24 hours following surgery, training with the stitches still in situ. Several athletes in his series returned to world-class performance, although the time after surgery of elite competition involvement was not outlined. ${ }^{2}$ The surgical procedure was a synovectomy of the crossover muscles that had hypertrophied. Williams stated the pathology to be a stenosing traumatic tenosynovitis, not a compartment syndrome variant.

In these presented elite rowers, the pathology found at surgery was consistent with a pathogenetic mechanism of hypertrophy of first compartment muscles (figure 1) leading to a hyperplastic fibrous sheath at the upper end of the muscle sheath (figure 2) that then acts as a tight rasping structure on the synovium of the second compartment tendons to produce an attrition tear of the synovium (figures 3 and 5 ), and subsequent true tendinitis

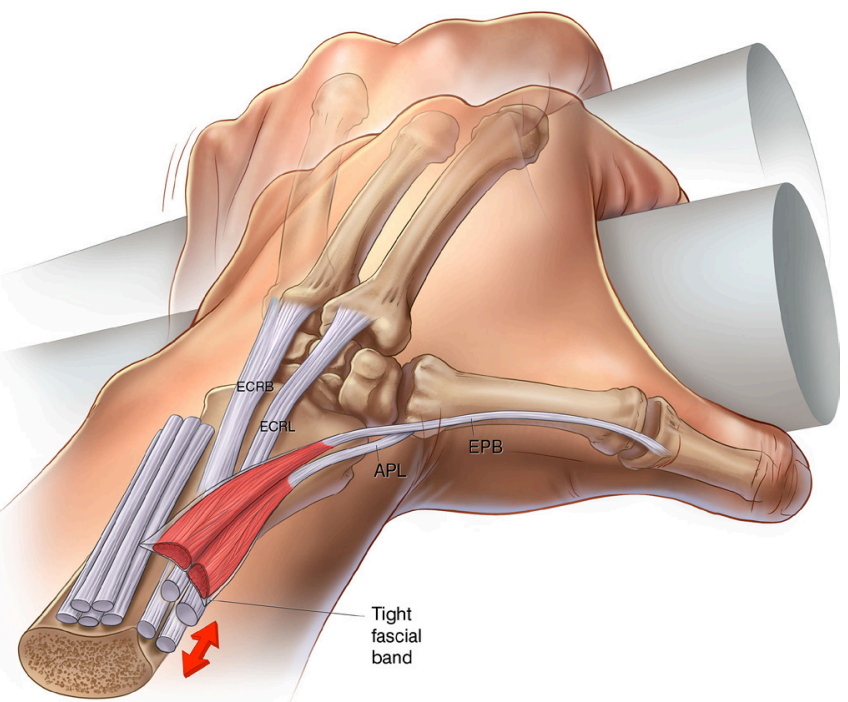

Figure 5 The sawing mechanism of the hypertrophied first compartment sheath in rowing. ECRB, extensor carpi radialis brevis; ECRL, ECR longus. with crepitus from the ECRL and ECRB tendons, respectively (figures 4 and 5). Hence, we propose a reasonably straight forward, but not previously described, pathogenetic mechanism for this condition, which is consistent with all parameters of the investigation, and which serves as a guide to early surgical debridement and recovery.

If we demonstrate the events diagrammatically, the overuse of the crossover (first compartment) muscles leads to hypertrophy (rather than compartment syndrome), a tight fascial band at the margin of the muscle sheath (figure 5). Because the compartment runs over the second compartment tendon sheaths in a convex fashion, this rubbing wears through the second compartment synovial sheath (figure 6). The fascia then rubs directly on the tendon, producing crepitus and pain (figure 7). The photos demonstrate the effects of the noted mechanism, with clear evidence of the defect in the

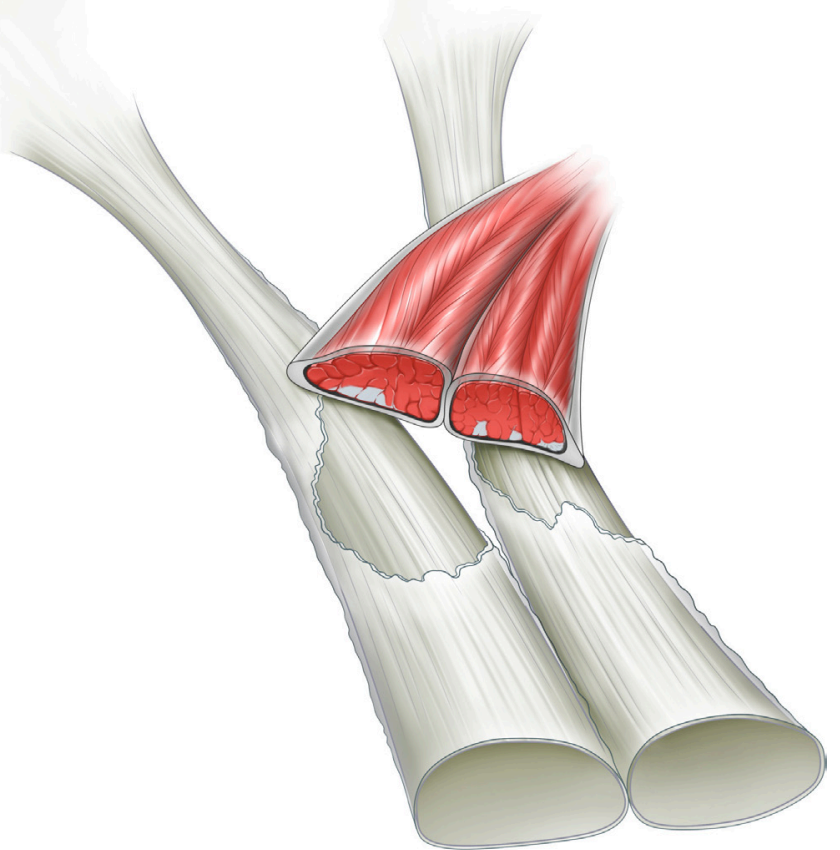

Figure 6 Cross-section of both compartments showing sharpened fascial edge of first compartment sheath over second compartment synovium. 


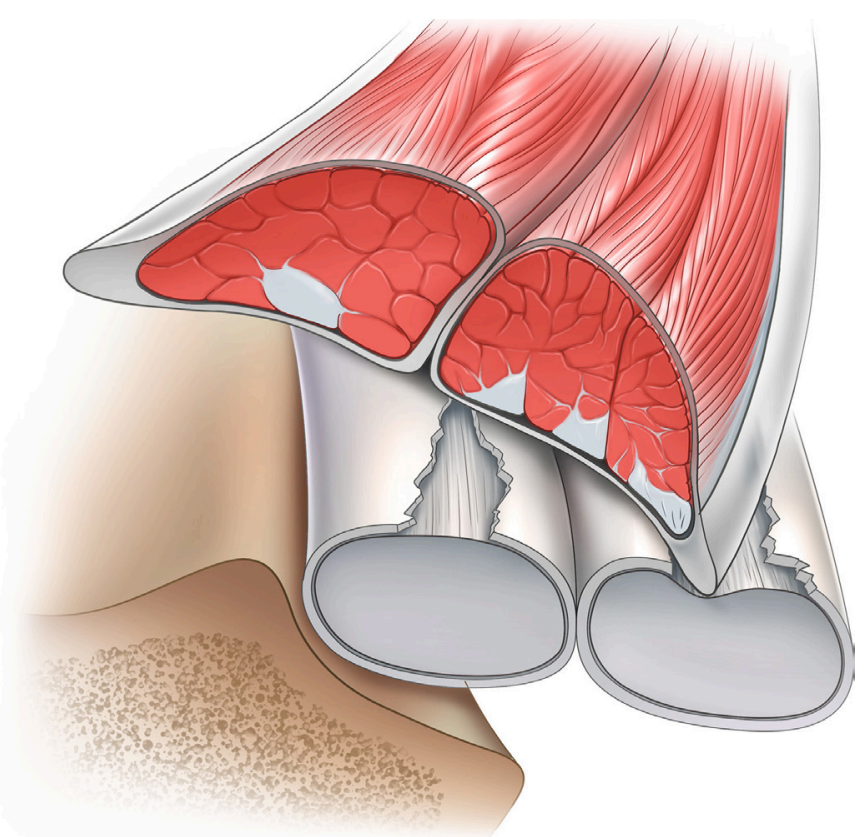

Figure 7 Schematic of resultant perforation of second compartment synovium.

second compartment synovium (figures 3 and 4) rather than stenosing tenosynovitis as previously reported.

Recent reviews of this topic have suggested that errors in technique are a common cause of the problem. ${ }^{16}$ However, most authors ${ }^{1-3} 5$ have suggested some form of overload as the main initiating factor. The pathologic changes in our patients are consistent with a fibrous response in the fascia around the first compartment musculature as a result of hypertrophy, which subsequently causes an attrition tear in the synovium of the long wrist extensors and leads to the development of a true tendinitis with crepitus with repetitive or prolonged use. This pathology is then analogous with an overuse syndrome, which can occur in both the sporting and work situations. $^{21}$

The return of rowers to medal in elite competition between 4 and 8 weeks after surgery shows that this intervention is a valid first alternative to rest, changes of technique and cortisone injection with possible subsequent relapse, but also with significant interruption to often rigorous team training schedules.

Surgical intervention in five of the six athletes has resulted in long-term symptom relief. All six athletes returned to competition in abbreviated rehabilitation programmes and three medalled at their immediate event, achieving career goals, and without recurrence of their symptoms. At an average of 3 years at last check, all but case five had a full recovery and no recurrence of symptoms despite the high initial workload. Case five was complicated by the non-related trauma and subsequent issues; however, this athlete successfully returned to international rowing racing at 3 weeks.

The simple excision of this tissue with an accelerated postoperative regime will not risk recurrent symptoms, and will allow almost immediate return to sport with very little deconditioning or biomechanical technique problems. We recommend consideration of early surgical intervention in the elite rower with impending time critical career goals to minimise downtime and continue with high-level function.

Acknowledgements Levent Efe provided graphic artworks and Hamish Anderson provided research and ethics support and assisted with postoperative treatment.

Contributors GH performed the surgery and developed the concept and wrote the manuscript. WB performed the relevant rehabilitation and reviewed the early versions of the paper. She passed away prior to the final manuscript submission. $\mathrm{LT}$ recorded the national squad data, revised and added to the manuscript and the data.

Funding The authors have not declared a specific grant for this research from any funding agency in the public, commercial or not-for-profit sectors.

Competing interests None declared.

Patient consent for publication Not required.

Provenance and peer review Not commissioned; externally peer reviewed. Data availability statement Data are available on reasonable request.

Open access This is an open access article distributed in accordance with the Creative Commons Attribution Non Commercial (CC BY-NC 4.0) license, which permits others to distribute, remix, adapt, build upon this work non-commercially, and license their derivative works on different terms, provided the original work is properly cited, appropriate credit is given, any changes made indicated, and the use is non-commercial. See: http://creativecommons.org/licenses/by-nc/4.0/.

\section{REFERENCES}

1. Howard N. PERITENDINITIS crepitans: a Muscle-Effort syndrome. JBJS 1937;19:447-59.

2. Williams JG. Surgical management of traumatic non-infective tenosynovitis of the wrist extensors. J Bone Joint Surg Br 1977;59B:408-10.

3. Grundberg AB, Reagan DS. Pathologic anatomy of the forearm: intersection syndrome. The Journal of Hand Surgery 1985;10:299-302.

4. Burman M. Stenosing tendovaginitis of the dorsal and volar compartments of the wrist. Archives of Surgery 1952;65:752-62.

5. Wood MB, Dobyns JH. Sports-related Extraarticular wrist syndromes. Clinical Orthopaedics and Related Research 1986;\&NA:93???102-102.

6. Drew MK, Trease L, Caneiro JP, et al. Normative MRI, ultrasound and muscle functional MRI findings in the forearms of asymptomatic elite rowers. Journal of science and medicine in sport / Sports Medicine Australia 2015.

7. Garnham AAM, Gropper P. Wrist hand and finger injuries. In: Brukner PKK, ed. Clinical sports medicine. 3rd Edition. Sydney: McGraw Hill, 2007: 308-39.

8. du Toit P, Sole G, Bowerbank P, et al. Incidence and causes of tenosynovitis of the wrist extensors in long distance paddle canoeists. British Journal of Sports Medicine 1999;33:105-9.

9. Costa CR, Morrison WB, Carrino JA. MRI features of intersection syndrome of the forearm. American Journal of Roentgenology 2003:181:1245-9.

10. De Maeseneer M, Marcelis S, Jager T, et al. Spectrum of normal and pathologic findings in the region of the first extensor compartment of the wrist: sonographic findings and correlations with dissections. Journal of ultrasound in medicine : official journal of the American Institute of Ultrasound in Medicine 2009;28:779-86.

11. Montechiarello S, Miozzi F, D'Ambrosio I, et al. The intersection syndrome: ultrasound findings and their diagnostic value. Journal of Ultrasound 2010:13:70-3.

12. de Lima JE, Kim H-J, Albertotti F, et al. Intersection syndrome: MR imaging with anatomic comparison of the distal forearm. Skeletal Radiology 2004;33:627-31.

13. Lee RP, Hatem SF, Recht MP. Extended MRI findings of intersection syndrome. Skeletal Radiology 2009;38:157-63.

14. Wulle C. Handchirurgie, Mikrochirurgie, plastische Chirurgie : Organ der Deutschsprachigen Arbeitsgemeinschaft fur Handchirurgie. Organ der Deutschsprachigen Arbeitsgemeinschaft fur Mikrochirurgie der Peripheren Nerven und Gefasse 1993;25:48-50. 
15. McAuliffe JA. Tendon disorders of the hand and wrist. $J$ Hand Surg Am 2010;35:846-53.

16. Rumball JS, Lebrun CM, Di Ciacca SR, et al. Rowing injuries. Sports Medicine 2005;35:537-55.

17. Hickey GJ, Fricker PA, McDONALD WA. Injuries to elite rowers over a 10-yr period. Medicine \&amp Science in Sports \&amp Exercise 1997;29:1567-72.

18. Neville VJ, Molloy J, Brooks JHM, et al. Epidemiology of injuries and illnesses in America's cup yacht racing. Br J Sports Med 2006:40:304-11.
19. Palmer DH, Lane-Larsen CL. Helicopter skiing wrist injuries. A case report of "bugaboo forearm". The American journal of sports medicine 1994;22:148-9.

20. Tagliafico AS, Ameri P, Michaud J, et al. Wrist injuries in nonprofessional tennis players: relationships with different grips. Am J Sports Med 2009;37:760-7.

21. Descatha A, Leproust $H$, Roure $P$, et al. Is the intersection syndrome is an occupational disease? Joint Bone Spine 2008;75:329-31. 